\title{
Acute myeloblastic leukaemia associated with solitary plasmacytoma of the ilium
}

\author{
D. Maharaj and G. Dolan \\ Department of Haematology, Royal Infirmary, Glasgow G4 OSF, UK.
}

\begin{abstract}
Summary: A 72 year old man developed acute myeloblastic leukaemia two years after he had been treated with local curative therapy and chemotherapy for a solitary plasma cytoma of the ilium.
\end{abstract}

\section{Introduction}

Localized plasmacytomas constitute less than $10 \%$ of malignant plasma cell dyscrasias. Some plasmacytomas develop singly and remain solitary either in bone marrow (solitary myeloma) or in soft tissues (extramedullary plasmacytomas). The association of multiple myeloma and acute non-lymphocytic leukaemia is well documented (Bersagel, 1982; Drivsholm et al., 1985). The occurrence of acute myeloid leukaemia in a patient with an untreated primary colonic plasmacytoma has also been reported (Ohmori et al., 1984). This is the first report of the occurrence of acute myeloblastic leukaemia following treatment of a solitary plasmacytoma without evidence of progression to multiple myeloma.

\section{Case history}

A 75 year old man presented in June 1980 with a 3month history of pain in the lower lumbar back and left hip. Examination revealed moderate limitation of movement at the lumbar spine. Investigations showed: haemoglobin $12.7 \mathrm{~g} / \mathrm{dl}$, white blood cell count $6.9 \times 10^{9} / 1$, platelet count $308 \times 10^{9} / 1$ with normal film, erythrocyte sedimentation rate $78 \mathrm{~mm}$ in the first hour. The following blood biochemical investigations were normal: urea and electrolytes, liver function tests, calcium, phosphate, alkaline phosphatase, albumin and total proteins. Immunoglobulin levels were $\operatorname{IgA} 2.2 \mathrm{~g} / 1, \mathrm{IgG} 8.6 \mathrm{~g} / 1, \mathrm{IgM} 0.6 \mathrm{~g} / 1$ and serum electrophoresis was also normal. Bence Jones protein was present in the urine $(2 \mathrm{~g} / 24 \mathrm{~h})$ and electrophoresis showed kappa light chains. Skeletal survey revealed an extensive multi-loculated lytic lesion with coarse trabecular markings in the left ilium. There were no other bony abnormalities. Histological examination

Correspondence: D. Maharaj, M.R.C.P. (UK), M.R.C. Path. Accepted: 3 July 1986 of a left iliac crest excision biopsy showed an extensive infiltrate of plasma cells. Sternal marrow aspirate and a trephine biopsy of the right iliac crest were normal.

These findings were consistent with a diagnosis of a localized plasmacytoma with probable sub-clinical dissemination because of the large amount of urinary Bence Jones protein. The patient was managed initially with melphalan and prednisolone. Reassessment after three courses showed symptomatic improvement but no change in Bence Jones proteinuria, and deterioration of renal function (urea $15.7 \mathrm{mmol} / \mathrm{l}$, creatinine $320 \mu \mathrm{mol} / \mathrm{l})$. He was then treated with localized radiotherapy (total $7,750 \mathrm{cGy}$ ) to the left ilium as well as oral melphalan and prednisolone. In January 1982 there was a reduction in Bence Jones proteinuria, improvement in renal function but no change in radiological appearances. Eleven months later chemotherapy was stopped and there was no evidence of deterioration at this time.

In November 1983, the patient was admitted with increasing tiredness and marked pallor. Full blood count showed a haemoglobin of $6.6 \mathrm{~g} / \mathrm{dl}$, white cell count $1.7 \times 10^{9} / 1$, with a differential count - mature neutrophils $57 \%$, metamyelocytes $21 \%$, myelocytes $8 \%$, blasts $4 \%$, lymphocytes $10 \%$ and 4 nucleated red cells per 100 white cells. The platelet count was reduced at $65 \times 10^{9} / 1$. Sternal marrow aspirate was hypercellular with $90 \%$ blasts and less than $2 \%$ plasma cells. Cytochemical examination showed that $90 \%$ of bone marrow cells were myeloblasts (Sudan Black and chloracetate esterase - positive, periodic acid Schiff and non-specific esterase - negative).

Biochemical investigations were as follows: immunoglobulins IgA $1.1 \mathrm{~g} / 1$, IgG $10.9 \mathrm{~g} / 1$, IgM $0.6 \mathrm{~g} / 1$, with normal serum electrophoresis. Urinary Bence Jones protein was present $(0.4 \mathrm{~g} / 24 \mathrm{~h})$ with persistence of kappa chains. Skeletal survey appearances were unchanged since initial presentation. The patient died of a chest infection three weeks after admission. There

(C) The Fellowship of Postgraduate Medicine, 1986 
was no evidence of dissemination of plasmacytoma to multiple myeloma at post-mortem.

\section{Discussion}

The prognosis of patients presenting with localized plasmacytomas is much better than that of patients with disseminated plasma cell dyscrasias such as multiple myeloma and plasma cell leukaemia (Woodruff et al., 1979; Wollersheim et al., 1984). Even cases of localized plasmacytoma with subsequent dissemination survive longer than those treated for overt multiple myeloma (Alexanian, 1980). Such data suggest that localized plasmacytoma is a disorder which is related to but distinct from multiple myeloma. There is as yet no reliable means of prospectively distinguishing patients with occult multiple myeloma and those with truly solitary plasmacytoma, and it is recommended that all patients with apparent solitary plasmacytoma must receive curative local therapy with surgery and high doses of radiation therapy (>5,000 cGy) (Woodruff et al., 1979; Bataille et al., 1981). In addition it has been suggested that patients with localized plasmacytomas who have evidence of sub-clinical dissemination with large amounts of monoclonal protein in serum or urine might benefit from early adjuvant chemotherapy (Bataille, 1982). However, there are no clinical trials to support this recommendation.

A major disadvantage of long-term chemotherapy is the possible occurrence of acute leukaemia. An in-

\section{References}

ALEXANIAN, R. (1980). Localised and indolent myeloma. Blood, 56, 521.

BATAILlE, R., SANY, J. \& SERRE, H. (1981). Plasmacytomas apparement solitaires des os: aspects cliniques et prognostiques (A propos de 114 Cas). La Nouvelle Presse Médicale, $10,407$.

BATAILLE, R. (1982). Localized plasmacytomas. Clinics in Hematology, 11, 113.

BERGSAGEL, D.E. (1982). Plasma cell neoplasms and acute leukemia. Clinics in Hematology, 11, 221.

DRIVSHOLM, A., LISSE, I. \& PREBEN, P. (1985). Development of acute non-lymphocytic leukaemia (ANLL) in myelomatosis. Scandinavian Journal of Haematology, 35, 35.

KYLE, R.A., PIERRE, R.V. \& BAYRD, E.D. (1970). Multiple myeloma and acute myelomonocytic leukemia. New En- creasing number of cases with both multiple myeloma and acute leukaemia have been published (Kyle et al., 1970; Rosner \& Gurnwald, 1984). The incidence of acute leukaemia in multiple myeloma has been reported to be between 100 and 230 times greater than the predicted incidence in normal individuals (Bergsagel, 1982). This increased incidence has been attributed to the use of cytostatic agents especially alkylating agents though a causal relationship is yet to be documented.

In our patient, the large amount of urinary Bence Jones protein at presentation suggested a high tumour mass and curative local therapy was supplemented with adjuvant chemotherapy. However there was no evidence of dissemination to multiple myeloma and this was further supported by the return of urinary protein levels to near normal after treatment. The development of acute myeloid leukaemia in our patient suggests that the use of alkylating agents in the treatment of solitary plasmacytomas should only be considered when there is evidence of overt dissemination to multiple myeloma. The high risk of acute leukaemia associated with the use of alkylating agents has to be balanced against the relatively good prognosis of solitary plasmacytomas. However, if early adjuvant chemotherapy is to be used in the treatment of those patients with localized plasmacytomas and evidence of sub-clinical dissemination then regimes including methyl prednisolone, dexamethasone, vincro istine and adriamycin which have not been implicate in the development of acute leukaemia should b considered.

gland Journal of Medicine, 283, 1121.

OHMORI, T., KONO, H., KAJIWARA, S., NORIMASA, N. \& TABEI, R. (1984). Primary colonic plasmacytoma associated with acute myelogenous leukaemia. American Journal of Gastroenterology, 79, 265.

ROSNER, F. \& GURNWALD, H.N. (1984). Simultaneous occurrence of multiple myeloma and acute myeloblastic leukaemia; Fact or myth? American Journal of Medicine, 76, 891 .

WOLLERSCHEIM, H.C.H., HOLDRINET, R.S.G. \& HAANEN, C. (1984). Clinical course and survival in 16 patients with localised plasmacytoma. Scandinavian Journal of Haematology, 32, 423.

WOODRUFF, R.K., MALPAS, J.S. \& WHITE, F.E. (1979). Solitary plasmacytoma. Cancer, $\cdot 43,2344$. 